\title{
Factor of safety of pile-stabilised slopes: an algorithm incorporating soill-arching effect
}

C. R. Neeraj MS

PhD Research Scholar, Department of Civil Engineering, Indian Institute of Technology Palakkad, Kerala, India (Orcid:0000-0001-9837-0496)
S. Thiyyakkandi PhD

Assistant Professor, Department of Civil Engineering, Indian Institute of Technology Palakkad, Kerala, India (Orcid:0000-0002-5857-9970)

(corresponding author: sudheesh@iitpkd.ac.in)

The current practice of factor of safety computation of pile-stabilised slopes depends substantially on either the extension of methods for normal slopes with the pile-contribution introduced as an additional term or finite-element modelling. Extending conventional methods to analyse pile-stabilised slopes fails to capture the key mechanisms like soil arching, gradual transfer of resistance offered by the pile through the slope, change in slip surface due to introduction of piles and so on. In this paper, a new algorithm is proposed to compute the factor of safety of pilestabilised slopes, in which the Morgenstern-Price method is modified to incorporate the effect of a pile. The resistance offered by the pile is obtained using a pressure-based method which considers the soil-arching effect in horizontal and vertical directions. The gradual propagation of this resistance offered by the pile is incorporated through an iterative procedure, unlike the conventional methods. The algorithm considers the change in slip surface due to the introduction of the pile. The factor of safety values computed using the proposed algorithm were found to be in close agreement with that obtained from finite-element modelling. Moreover, a simple technique to determine the optimal location of stabilising piles and pile-spacing is also presented.

Keywords: failure/piles and piling/slope stabilisation/slopes

\section{Notations}

$D \quad$ diameter of stabilising piles

E modulus of elasticity

$E_{i} \quad$ normal inter-slice force

$F_{s} \quad$ Factor of safety of slope

$H \quad$ depth of the pile above the slip surface

$K_{\text {an }} \quad$ new coefficient of lateral earth pressure incorporating soil arching

$K_{c} \quad$ horizontal seismic coefficient

$M_{S} \quad$ additional moment due to installation of the piles

$N_{i}^{\prime} \quad$ effective normal force on the base lateral resistance offered by the pile per unit depth resultant lateral force acting on post-arching zone resultant reaction on pre-arching zone resultant lateral force on pile external force on $\left(i^{\text {th }}\right)$ slice mobilized shear resistance on the base of a slice resultant pore water force self-weight of $i^{\text {th }}$ slice inter-slice shear force width of $i^{\text {th }}$ slice cohesion of the soil height of $i^{\text {th }}$ slice length of horizontal arching zone ratio of centre-to-centre spacing and pile diameter centre-to-centre spacing between piles average pore water pressure base inclination of $i^{\text {th }}$ slice angle of soil slope with horizontal unit weight of soil spacing coefficient $\lambda$ scale factor

$\lambda_{\mathrm{m}} \quad$ proposed scale factor

$\mu \quad$ Poisson's ratio

$\phi \quad$ angle of internal friction of soil

$\Psi \quad$ angle of dilatancy of soil

$\sigma_{i} \quad$ radial stress on the inner arch of horizontal arching zone

$\bar{\sigma}_{\mathrm{v}} \quad$ average vertical stress on a differential element $d z$

\section{Introduction}

The stability of slopes is one of the fundamental problems in geotechnical engineering as their delicate balance is often disrupted by natural or man-made causes. Furthermore, the increasing demand for engineered cut-and-fills, construction near or on slopes and so on, has increased the need to understand the mechanism of slope failure and develop techniques to stabilise the slopes. Stability of slopes depends on the balance between a driving force that causes failure and a resisting force that is developed against it. All the slope stabilisation methods basically try to reduce the driving force or increase the resisting force or both. One of the operative techniques employed for stabilisation of slopes and prevention of excessive soil movement is using stabilising piles in row(s) (Ashour and Ardalan, 2012; Ausilio et al., 2001; Cai and Ugai, 2000; Hassiotis et al., 1997; Ito and Matsui, 1975; Kourkoulis et al. 2011a; Liang et al. 2014; Lirer, 2012; Neeraj and Thiyyakkandi, 2020). In practice, the piles are installed well beyond the potential slip surface to the firm ground beneath it to arrest the possible sliding of unstable soil mass. The piles act as a cantilever beam that takes the lateral forces due to the sliding soil mass and transfer them to the stable ground underneath it (Ellis et al., 2010; Liang and Zeng, 2002). This additional resistance provided by the piles stabilises the slope, thus 
improving its factor of safety $\left(F_{s}\right)$ against failure. The computation of $F_{S}$ of pile-stabilised slopes is conventionally done by extending the methods used for analysis of normal slopes to incorporate the additional forces generated due to installation of piles.

The stability of normal slopes can be analysed by numerous methods such as the limit analysis method, variational calculus method, strength reduction method, limit equilibrium method and so on (Atarigaya, 2016). The need for considering different forces (e.g. body force, pore water pressure, etc.) and diverse soil types in the stability analysis of slopes invalidates the use of conventional methods in the mechanics of continua, and consequently, the limit equilibrium method is commonly adopted (Morgenstern and Price, 1965). One of the earliest known and most widely used concepts of limit equilibrium is explained through method of slices owing to the ease of computation (Ahmed, 2017; Atarigaya, 2016; Duncan, 1996; Firat, 2009; Hassiotis et al., 1997; Tsuchida and Athapaththu 2014; Zhu et al., 2005). The analysis is done by dividing the slope into a number of slices to find out the factor of safety of the slope. Various methods commonly used for formulation of $F_{S}$ in the method of slices are the Fellenius Swedish circle or ordinary method, Bishop's simplified method, Janbu method, Spencer method and Morgenstern-Price method. All these limit equilibrium methods use the Mohr-Coulomb criterion to determine the shear strength of soil along the failure surface. The choice of method depends largely on the type of soil and the required accuracy of the work. The most widely used method for the analysis of a generalised slip surface is the Morgenstern-Price method (Ahmed, 2017; Atarigaya, 2016; Firat, 2009; Griffiths and Lane, 1999). This method considers both moment and force equilibriums to produce a non-linear indeterminate equation for $F_{s}$. The equation is made determinate by assuming a function that relates the inter-slice shear force to inter-slice normal force.

The methods mentioned above are applicable for the case of normal slopes that are not stabilised by piles. At present, the study of pile-stabilised slopes is generally carried out by extending these conventional methods (Di Laora et al., 2017; Firat, 2009; 1995; Jeong et al., 2003; Kourkoulis et al., 2011; Lee et al., 1995, Summersgill et al., 2018). The resistance offered by the piles is added as an additional term in the formulation of $F_{s}$, which does not account for the propagation of reactive force through soil. A major issue in this approach is that the critical slip surface considered is the same as that of non-stabilised soil slopes (Firat, 2009; Kourkoulis et al., 2011; Lee et al., 1995; Summersgill et al., 2018). However, in reality, due to the introduction of piles, the critical slip surface changes and this modified surface needs to be considered while computing the $F_{s}$. Also, the conventional methods fail to incorporate the effect of location of piles along the slopes (Hassiotis et al., 1997; Lirer, 2012; Neeraj, 2019; Summersgill et al., 2018). In the present study, the Morgenstern-Price method is modified using the method of slices to adopt for the analysis of pile-stabilised slopes such that the cumulative effect of lateral resistance offered by the pile on each slice is accounted for. An algorithm is developed to compute the $F_{S}$ of the pile-stabilised slope considering the modified critical slip surface. The proposed algorithm can be easily switched to use for both normal slopes and pile stabilised slopes. Finite-element modelling of both normal and pile-stabilised slopes was carried out and the obtained $F_{s}$ values were used to validate the proposed algorithm. The variation of $F_{s}$ with the location of the pile along the slope was studied. Subsequently, a simple technique to determine the optimal pile location is explained.

The $F_{s}$ computation using the proposed algorithm requires accurate determination of lateral resistance offered by the stabilising piles. Due to the resistance from the pile and differential movement of soil in between the piles, the soil-arching effect plays a key role in the load-transfer mechanism of pile-stabilised slopes. Several methods have been proposed in the past to estimate the lateral resistance offered by the row of piles incorporating the effect of soil arching. One of the pioneering attempts to model the soil-arching effect due to the differential lateral deformation of soil between the piles in the horizontal direction (termed as 'squeezing effect') was by Ito and Matsui (1975). However, the method does not consider the rotation of principal stresses due to soil arching. Most of the methods developed afterward have adopted or modified the 'squeezing concept' considered by Ito and Matsui (1975) (Frrat 2009; HarropWilliams, 1989; He et al., 2015a; He et al., 2015b; Li and Wei, 2018; Song et al., 2012; Won et al., 2005). As the soil in front of the piles deforms vertically, the lateral earth pressure distribution adjacent to the stabilising piles will become non-linear due to the vertical arching. Adopting the formulation of Ito and Matsui (1975), He et al. (2015a) presented an analytical method to determine the non-linear pile resistance in sandy slopes incorporating vertical arching. The method was extended by He et al. (2015b) for $c-\phi$ soil; however, it does not account for the effect of slope angle. In reality, both horizontal and vertical arching need to be considered to determine the lateral resistance offered by the stabilising piles. Recently, Neeraj and Thiyyakkandi (2020) presented a general method (for $c-\phi$ soil) to determine the lateral pile resistance incorporating the effect of soil arching in horizontal and vertical directions. The method also considers the effect of slope angle $(\beta)$ in the design. In this work, the method of Neeraj and Thiyyakkandi (2020) is extended to model the gradual propagation of pile resistance as explained in subsequent sections.

\section{Lateral resistance offered by the row of piles}

An analytical method to obtain the lateral resistance offered by the row of piles considering the effect of soil arching in both the horizontal and vertical direction was proposed by Neeraj and Thiyyakkandi (2020). The stress state of the soil-arching zone in the horizontal direction is presented in Figure 1. The resistance offered by the stabilising piles is given by:

1. $P=\sigma_{i}(\Lambda+1) D+\frac{2 c \sqrt{N}}{N-1} \Lambda D$ 


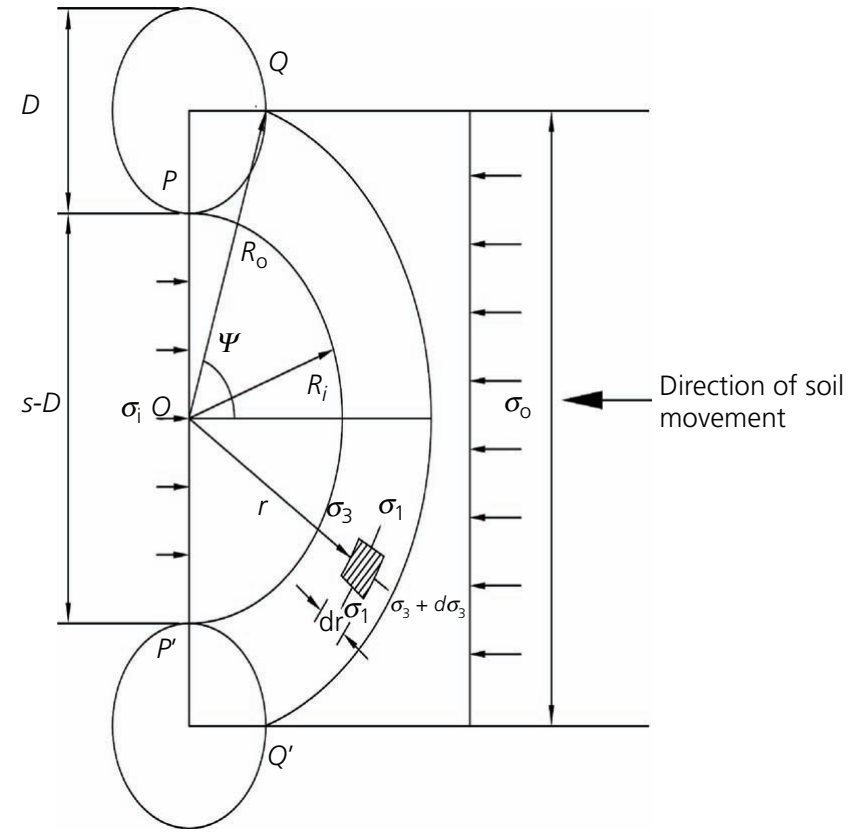

Figure 1. Horizontal arching zone in pile-stabilised slopes

Where, $\Lambda$ is the spacing coefficient given by, $\Lambda=\left[\left(\frac{\sqrt{n^{2}+1}}{n-1}\right)^{N-1}-\right.$ 1] $n$; here $n$ is the ratio of pile spacing to the diameter of the piles $(n=s / D)$ and $N=\tan ^{2} 45+\phi / 2$. The term $c$ represents the cohesion of the soil, and $\phi$ the angle of internal friction. The stress, $\sigma_{i}$, acting along the central plane of pile row is a function of average vertical stress $\left(\bar{\sigma}_{\mathrm{v}}\right)$ as given by:

2. $\sigma_{i}=K_{\mathrm{an}} \bar{\sigma}_{\mathrm{v}}+T$

Where:

$K_{\text {an }}=\frac{\cos \left(\theta_{\mathrm{w}}+\xi\right) \cos \beta}{\cos (\beta+\xi)}\left[\frac{3\left(N \cos ^{2} \theta_{\mathrm{w}}+\sin ^{2} \theta_{\mathrm{w}}\right)}{3 N-(N-1) \cos ^{2} \theta_{\mathrm{w}}}\right]$

$T=\frac{2 c}{\sqrt{N}}\left[\frac{\cos ^{2} \theta_{\mathrm{w}}\left(3\left(N \cos ^{2} \theta_{\mathrm{w}}+\sin ^{2} \theta_{\mathrm{w}}\right)\right)}{3 N-(N-1) \cos ^{2} \theta_{\mathrm{w}}}-\sin ^{2} \theta_{\mathrm{w}}\right]$

The stress state including the direction of the major and minor principal stresses after vertical arching in the active plastic zone behind the row of piles is shown in Figure 2. A differential element $E F F^{\prime} E^{\prime}$ is assumed to take a circular shape due to vertical arching caused by the shear resistance developed along the vertical plane $\mathrm{OB}$. An intricate analysis considering the force equilibrium of the differential element results in the formulation of an expression for average vertical stress, $\bar{\sigma}_{\mathrm{v}}$, given by (Figure 2):

$$
\begin{aligned}
\bar{\sigma}_{\mathrm{v}}= & \frac{\gamma \cos \beta H}{1-C_{1}}\left[\left(1-\frac{z}{H}\right)^{C_{1}}-\left(1-\frac{z}{H}\right)\right] \\
& +\frac{C_{2}}{C_{1}}\left[\left(1-\frac{z}{H}\right)^{C_{1}}-1\right]
\end{aligned}
$$

Where:

$$
\begin{aligned}
C_{1} & =\left(K_{\mathrm{an}} \tan \phi-K_{\mathrm{an}} \tan \beta+m\right) \frac{\sin \theta}{\cos \theta_{1}} ; m=\frac{K_{\mathrm{an}}}{N \cos ^{2} \theta+\sin ^{2} \theta} \frac{\sin \xi \cos \beta}{\cos (\xi+\beta)} \\
C_{2} & =\left(T \tan \phi-K_{\mathrm{an}} \tan \beta+t\right) \frac{\sin \theta}{\cos \theta_{1}} ; \\
t & =c+\left(\frac{T+2 c \sin ^{2} \theta / \sqrt{N}}{N \cos ^{2} \theta+\sin ^{2} \theta}\right) \frac{\sin \xi \cos \beta}{\cos (\xi+\beta)}
\end{aligned}
$$

where, $\theta$ is the angle between the slip plane and the slope surface; $\theta_{1}$ is the angle between the slip plane and the horizontal; $\beta$ is the slope angle; and $\xi$ is the angle between the major principal stress and vertical at point where the differential element $d z$ intersects the slip plane; which are given by:

$\xi=\frac{\pi}{4}+\frac{\phi}{2}-\theta_{1} ; \theta=\frac{1}{2}\left(\phi-\beta+\cos ^{-1} \frac{\sin \beta}{\sin \phi}\right) ;$ and $\theta_{1}=\frac{1}{2}(\phi+\beta+$ $\left.\cos ^{-1} \frac{\sin \beta}{\sin \phi}\right)$

The average vertical stress $\left(\bar{\sigma}_{\mathrm{v}}\right)$ varies non-linearly with depth of the pile due to the vertical arching of soil. The detailed derivation of Equation 3 is presented in Appendix A.

The resultant force $\left(P_{r}\right)$ offered by the row of piles can be obtained by integrating Equation 1 with respect to the depth of the pile:

$$
\begin{aligned}
P_{r}= & D(\Lambda+1) K_{\text {an }}\left[\frac{\gamma \cos \beta H^{2}}{1-C_{1}}\left(\frac{1}{1+C_{1}}-\frac{1}{2}\right)\right. \\
& \left.+\frac{C_{2} H}{C_{1}}\left(\frac{1}{1+C_{1}}-1\right)\right]+T D(\Lambda+1) H \\
& +\frac{2 c \sqrt{N} \Lambda D H}{N-1}
\end{aligned}
$$

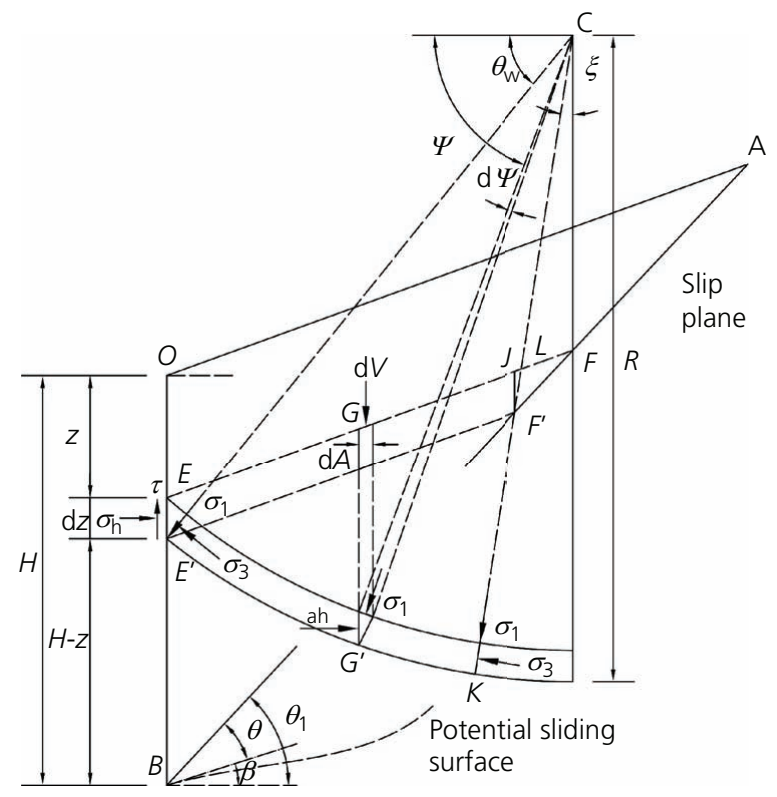

Figure 2. Stress state of vertical arching zone in front of pile row 
Further details about the derivations of Equations 1-4 can be found in the paper by Neeraj and Thiyyakkandi (2020). The analytical method described above is adopted to obtain the lateral resistance offered by piles. The method is further extended in this work to be used in the determination of $F_{S}$ of pile-stabilised slopes as explained in the following section.

\section{Analytical solution for safety analysis}

As mentioned in the Introduction, the Morgenstern-Price method is used in this study to analyse slope stability. According to Morgenstern and Price (1965), the inter-slice shear forces $\left(X_{i}\right)$ can be related to inter-slice normal forces $\left(E_{i}\right)$ by a predefined function $f(x)$ as given in Equation 5. The direction of inter-slice forces varies according to the assumed function.

\section{5. $X_{i}=E_{i} \lambda f(x)$}

Where:

$f(x)=$ inter-slice function that varies continuously along the slip surface

$\lambda=$ scale factor for the assumed function

Theoretically, the force function $f(x)$ can take any form. However, the nature of soil imposes certain range of functions that can be rationally used for all practical purposes (Morgenstern and Price, 1965). Commonly used functions are constant, half-sine, trapezoidal, user-defined, and so on. In this analysis, $f(x)$ is assumed as a halfsine function. An algorithm, based on the Morgenstern-Price method, developed by Zhu et al. (2005) to determine the $F_{s}$ for soil slopes that are not stabilised by piles is modified to incorporate the effects of additional reactive forces generated due to the introduction of stabilising piles. The solution is developed such that both moment equilibrium and force equilibrium are satisfied.

Figure 3 shows the free-body diagram of a typical slice $\left(i^{\text {th }}\right)$ with height $h_{i}$, width $b_{i}$ and base inclination $\alpha_{i}$. The slice is subjected to a self-weight $W_{i}$ and seismic force $K_{c} W_{i}$, where $K_{c}$ is the horizontal seismic coefficient, with external force $Q_{i}$ acting at an angle $\omega_{i}$ to the vertical, resultant pore water force $U_{i}=u_{i} b_{i} \sec \alpha_{i}$, where $u_{i}$ is the average pore water pressure, effective normal force on the base $N_{i}^{\prime}$ and mobilized shear resistance $S_{i}=\left(N_{i}^{\prime} \tan \phi_{i}^{\prime}+c_{i}^{\prime} b_{i} \sec \alpha_{i}\right) / F_{s}$, where $\phi_{i}^{\prime}$ is the effective angle of internal friction, $c_{i}^{\prime}$ is the cohesion along the base of the slice and $F_{s}$ is the factor of safety for the slip surface. $F_{S}$ is assumed to be constant along a slip surface. The soil slice is also subjected to normal inter-slice forces $E_{i}$ and $E_{i-1}$ on the left and right boundaries of the slice at a height $z_{i}$ and $z_{i-1}$ from the bottom, respectively. Inter-slice shear forces are calculated using Equation 5.

The equation for $F_{s}$ developed by Zhu et al. (2005) based on the Morgenstern-Price method for soil slopes that are not stabilised by piles is as given below.

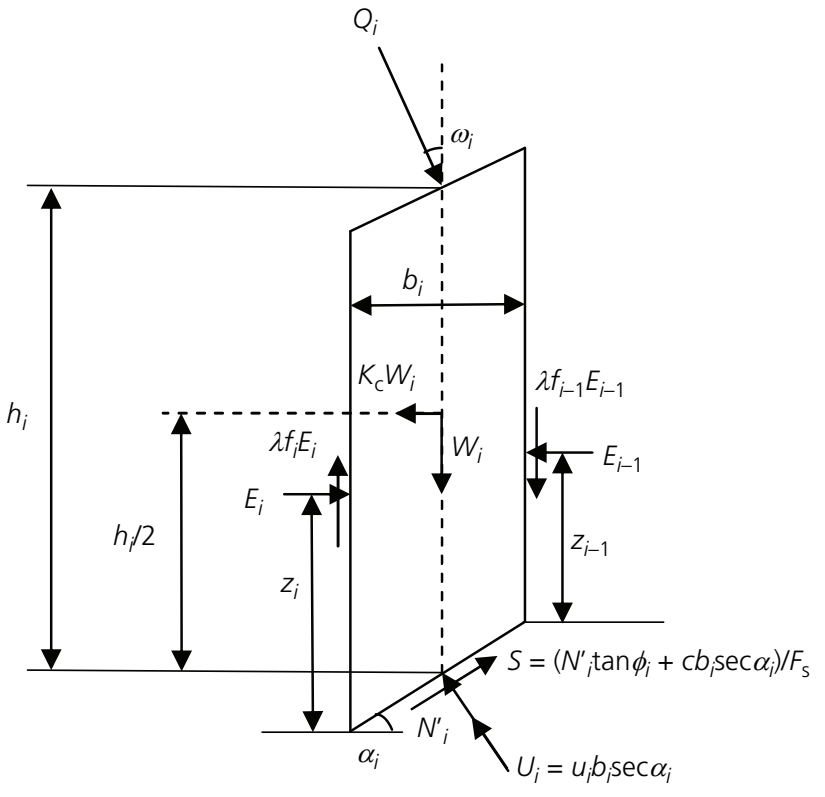

Figure 3. Free body diagram of a typical slice

Where:

$\lambda=\frac{\sum_{i=1}^{n}\left[b_{i}\left(E_{i}+E_{i-1}\right) \tan \alpha_{i}+K_{c} W_{i} h_{i}+2 Q_{i} \sin \omega_{i} h_{i}\right]}{\sum_{i=1}^{n}\left[b_{i}\left(f_{i} E_{i}+F_{i-1} E_{i-1}\right)\right]}$

8.

$$
\begin{aligned}
\Psi_{i}= & {\left[\left(\sin \alpha_{i}-\lambda f_{i-1} \cos \alpha_{i}\right) \tan \phi_{i}^{\prime}\right.} \\
& \left.+\left(\cos \alpha_{i}+\lambda f_{i-1} \sin \alpha\right) F_{s}\right] \Phi_{i-1}
\end{aligned}
$$

9. $E_{i}=\left(\Psi_{i-1} E_{i-1} \Phi_{\mathrm{i}-1}+F_{s} T_{i}-R_{i}\right) / \Phi_{i}$

10. $\begin{aligned} \Phi_{i-1}= & \left(\sin \alpha_{i-1}-\lambda f_{i-1} \cos \alpha_{i}\right) \tan \phi_{i-1}^{\prime} \\ & +\left(\cos \alpha_{i-1}+\lambda f_{i-1} \sin \alpha_{i-1}\right) F_{s}\end{aligned}$ 
$R_{i}=\left[W_{i} \cos \alpha_{i}-K_{c} W_{i} \sin \alpha_{i}+Q_{i} \cos \left(\omega_{i}-\alpha_{i}\right)-U_{i}\right] \tan \phi_{i}^{\prime}$ $+c_{i}^{\prime} b_{i} \sec \alpha_{i}$

12.

13. $T_{i}=W_{i} \sin \alpha_{i}+K_{c} W_{i} \cos \alpha_{i}-Q_{i} \sin \left(\omega_{i}-\alpha_{i}\right)$

In reality, $R_{i}$ is sum of the components of all the forces acting on a slice contributing to the resisting force except the inter-slice normal forces, and $T_{i}$ is sum of all the forces that contribute to the driving force that cause instability. As the $F_{s}$ term exists on both sides of Equation 6, an iterative procedure has to be adopted to solve for $F_{s}$, with an assumed value in the first trial.

To incorporate the influence of stabilising piles in the safety analysis of slopes, a pile-stabilised slope as shown in Figure 4 with pile located at the $k^{\text {th }}$ slice is considered. The slope is demarcated into three zones, namely, the pre-arching zone, the arching zone and the post-arching zone. The region $k$ in Figure 4 represents the arching zone. The $(k-1)^{\text {th }}$ and $(k+1)^{\text {th }}$ slices are located to the right and left of the arching zone, respectively.

Figure 5 shows an enlarged view of the arching zone and the adjacent slices with the additional forces that occurs due to the introduction of piles. It should be noted that all the forces shown in Figure 3 also act on these slices, although they are omitted in
Figure 5 to improve clarity. The width of the $k^{\text {th }}$ slice is assumed to be the length of horizontal arching zone (Figure 1), given by:

14. $l_{\mathrm{a}}=\frac{D}{2} \sqrt{n^{2}+1}$

From the analytical solutions presented in the previous section, the resultant pile force $P_{\mathrm{r}}$ is the difference between the force $P_{\mathrm{o}}$ acting on the right edge of arching zone and the force $P_{\mathrm{i}}$ acting on the left edge of the arching zone (Neeraj, 2019).

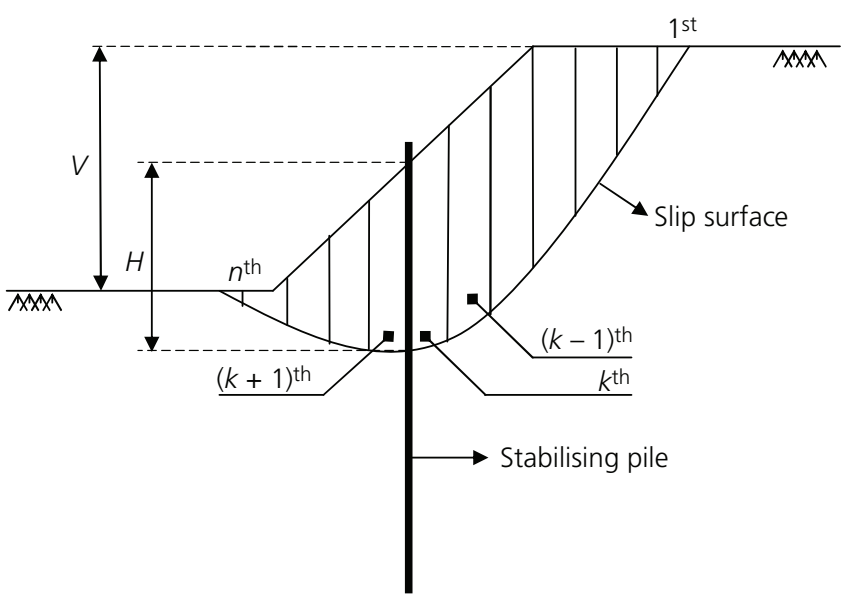

Figure 4. Pile-stabilised slope divided into slices

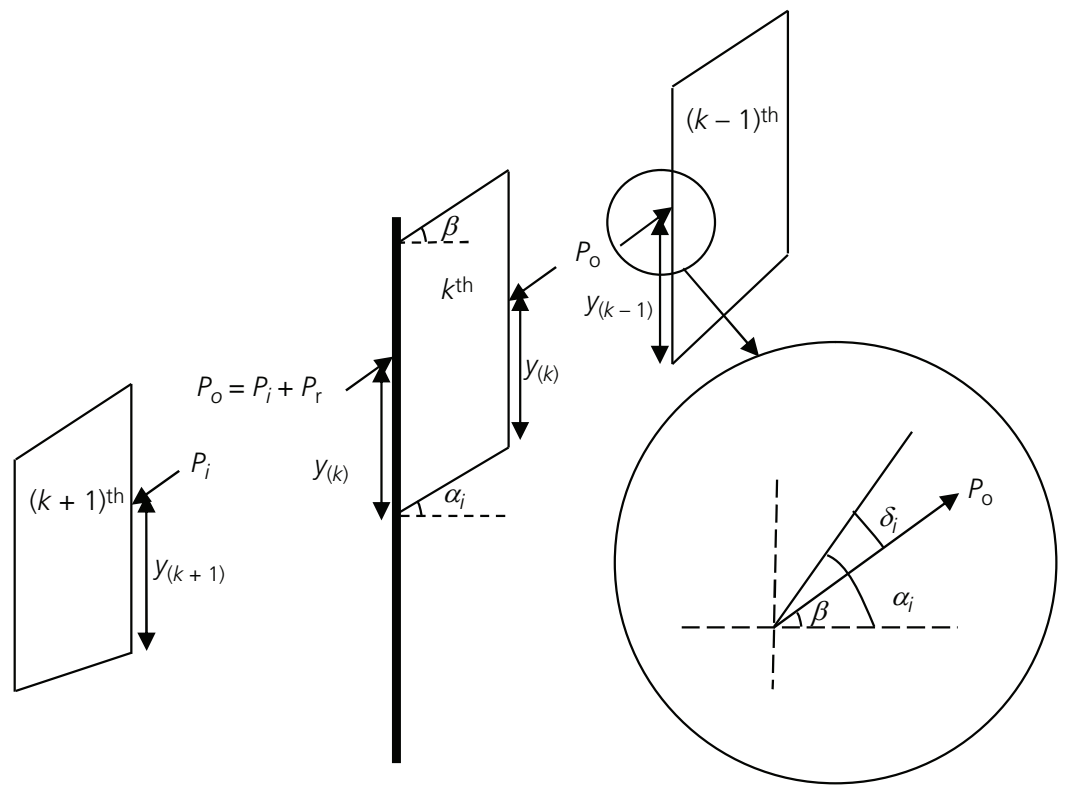

Figure 5. $(k+1)^{\text {th }}, k^{\text {th }}$ and $(k-1)^{\text {th }}$ slices 


$$
\begin{aligned}
P_{\mathrm{o}}= & n D H\left[( \frac { \sqrt { n ^ { 2 } + 1 } } { n - 1 } ) ^ { N - 1 } \left\{\frac{K_{\mathrm{an}} \gamma H \cos \beta}{1-C_{1}}\right.\right. \\
& \left.\left(\frac{1}{1+C_{1}}-\frac{1}{2}\right)+\frac{C_{2}}{C_{1}}\left(\frac{1}{1+C_{1}}-1\right)+T\right\} \\
& \left.+\frac{2 \mathrm{c} \sqrt{\mathrm{N}}}{\mathrm{N}-1}\left\{\left(\frac{\sqrt{n^{2}+1}}{n-1}\right)^{N-1}-1\right\}\right]
\end{aligned}
$$

15.

16.

$$
\begin{aligned}
P_{\mathrm{i}}= & (n-1) D H\left[\frac{K_{\mathrm{an}} \gamma H \cos \beta}{1-C_{1}}\left(\frac{1}{1+C_{1}}-\frac{1}{2}\right)\right. \\
& \left.+\frac{C_{2}}{C_{1}}\left(\frac{1}{1+C_{1}}-1\right)+T\right]
\end{aligned}
$$

The points of application of lateral thrusts $P_{\mathrm{o}}$ and $P_{\mathrm{i}}$ are given by $y_{k-1}=M_{\mathrm{o}} / P_{\mathrm{o}}$, and $y_{k+1}=M_{\mathrm{i}} / P_{\mathrm{i}}$, respectively, where $M_{\mathrm{o}}$ and $M_{\mathrm{i}}$ are corresponding moments along the slip surface. The detailed derivation of resultant forces $\left(P_{\mathrm{o}}\right.$ and $\left.P_{\mathrm{i}}\right)$ and moments $\left(M_{\mathrm{o}}\right.$ and $M_{\mathrm{i}}$ ) in the pre-arching and post-arching zones and the points of action $\left(y_{k-1}\right.$ and $\left.y_{k+1}\right)$ is presented in Appendix B.

The forces $P_{\mathrm{o}}$ and $P_{\mathrm{i}}$ are considered as external forces acting on the corresponding slices. They are resolved in the normal and tangential direction with respect to base of each slice and incorporated in $R_{\mathrm{i}}$ and $T_{\mathrm{i}}$ of corresponding slices as shown in Equations 17-20.

17

$$
\begin{aligned}
R_{k-1}= & {\left[W_{k-1} \cos \alpha_{k-1}-K_{c} W_{k-1} \sin \alpha_{k-1}\right.} \\
& +Q_{k-1} \cos \left(\omega_{k-1}-\alpha_{k-1}-1\right)-U_{k-1} \\
& \left.+\frac{P_{o}}{S} \sin \delta\right] \tan \phi^{\prime}+c_{k-1} b_{k-1} \sec \alpha_{k-1}
\end{aligned}
$$

$$
\begin{aligned}
T_{k-1}= & {\left[W_{k-1} \sin \alpha_{k-1}+K_{c} W_{k-1} \cos \alpha_{k-1}\right.} \\
& \left.+Q_{k-1} \sin \left(\omega_{k-1}-\alpha_{k-1}-1\right)-\frac{P_{o}}{s} \cos \delta\right]
\end{aligned}
$$

$$
\begin{aligned}
R_{k+1}= & {\left[W_{k+1} \cos \alpha_{k+1}-K_{c} W_{k+1} \sin \alpha_{k+1}\right.} \\
& +Q_{k+1} \cos \left(\omega_{k+1}-\alpha_{k+1}-1\right)-U_{k+1} \\
& \left.-\frac{P_{i}}{s-D} \sin \delta\right] \tan \phi^{\prime}+c_{k+1} b_{k+1} \sec \alpha_{k+1}
\end{aligned}
$$

20.

$$
\begin{aligned}
T_{k+1}= & {\left[W_{k+1} \sin \alpha_{k+1}+K_{c} W_{k+1} \cos \alpha_{k+1}\right.} \\
& +Q_{k+1} \sin \left(\omega_{k+1}-\alpha_{k-1}-1\right) \\
& \left.+\frac{P_{i}}{s-D} \cos \delta\right]
\end{aligned}
$$

where, $\delta=|\alpha-\beta|$ is the inclination of resultant additional force $\left(P_{\mathrm{o}}\right.$ or $\left.P_{\mathrm{i}}\right)$ with reference to the respective slice base as shown in Figure 5. Since the $k^{\text {th }}$ slice has equal forces acting from both sides $\left(P_{\mathrm{i}}+P_{\mathrm{r}}=P_{\mathrm{o}}\right.$, on the right edge and $P_{\mathrm{o}}$ on the left edge), $R_{k}$ and $T_{k}$ remain unchanged. However, the moment equilibrium of the slice is influenced by these forces as their lines of action differ. Specifically, an additional moment $M_{\mathrm{a}}$ is generated as given in Equation 21.

$$
\begin{aligned}
M_{\mathrm{a}}= & {\left[y_{k+1}\left\{\frac{P_{\mathrm{i}}}{s-D}-\frac{P_{\mathrm{o}}}{s}\right\}\right.} \\
& +\frac{P_{\mathrm{o}}}{s}\left\{b_{k} \tan \alpha_{k}+\frac{b_{k-1}}{2} \tan \alpha_{k-1}\right\} \\
& \left.+\frac{P_{i} b_{k+1}}{2(s-D)} \tan \alpha_{k+1}\right] \cos \beta
\end{aligned}
$$

Since the present method does not consider the pile's contribution as an additional component explicitly, the equation for $F_{s}$ (Equation 6) remains the same. However, the scale factor $\lambda$ needs to be modified to incorporate the additional moment $M_{\mathrm{a}}$ (Equation 21) developed on $k^{\text {th }}$ slice as follows,

$$
\lambda_{\mathrm{m}}=\frac{\sum_{i=1}^{n}\left[b_{i}\left(E_{i}+E_{i-1}\right) \tan \alpha_{i}+K_{c} W_{i} h_{i}+2 Q_{i} \sin \omega_{i} h_{i}\right]+M_{\mathrm{a}}}{\sum_{i=1}^{n}\left[b_{i}\left(f_{i} E_{i}+f_{i-1} E_{i-1}\right)\right]}
$$

The modified scale factor, $\lambda_{\mathrm{m}}$, has to be used in Equations 7,10 and 11 for $F_{S}$ calculation. 


\section{Algorithm to obtain factor of safety}

As indicated earlier, an iterative procedure is required to solve for the factor of safety. An iterative algorithm was developed for determining the critical slip surface and corresponding $F_{s}$ for a given pilestabilised slope. The steps involved in the iteration are as follows.

1. Input the slope geometry (height, $V$ and slope angle, $\beta$ ); soil properties $(\gamma, c$ and $\phi)$; and pile parameters $(D$ and $S)$.

2. Divide the whole slope into a number of slices.

3. Input pile location $(k)$ and compute the length of the soil-arching zone $\left(l_{\mathrm{a}}\right)$.

4. Choose an arbitrary slip surface and input entry and exit points.

5. Calculate the resultant forces acting on $k^{\text {th }},(k-1)^{\text {th }}$ and $(k+1)^{\text {th }}$ slices $\left(P_{\mathrm{r}}, P_{\mathrm{o}}\right.$ and $\left.P_{\mathrm{i}}\right)$ and the additional moment $\left(M_{\mathrm{a}}\right)$ developed due to the introduction of the piles, using Equations $4,15,16$, and 21, respectively.

6. Calculate $R_{i}$ and $T_{i}$ for all the slices using Equations 12 and 13 , respectively.

7. Modify $R_{i}$ and $T_{i}$ for $(k-1)^{\text {th }}$ slice and $(k+1)^{\text {th }}$ slice using Equations 17-20.

8. Define the inter-slice function $f(x)$. A half-sine function is assumed here:

$f(x)=\sin \left[\pi\left(\frac{x-x_{\min }}{x_{\max }-x_{\min }}\right)\right]$

where, $x_{\max }$ and $x_{\min }$ are abscissa of entry and exit points of the failure surface, respectively, and $x$ denotes the abscissa of midpoint of each slice.

9. Assume an initial value for $F_{s}$ and $\lambda_{\mathrm{m}}$. The number of iterations required depends on the initial values assumed. However, the final values of $F_{s}$ and $\lambda_{\mathrm{m}}$ do not vary with the assumed initial values. An effective transfer of inter-slice normal force requires the assumed $F_{s}$ to satisfy Equation 7 (Zhu et al., 2005). In general, for the first iteration, it can be assumed that $F_{S}=1$ and $\lambda_{\mathrm{m}}=0$.

10. Calculate $\Psi_{i}$ and $\Phi_{i}$ and for all slices using Equations 7 and 11.

11. Calculate $F_{s}$ using Equation 6.

12. With $F_{s}$ obtained from step 11 and the assumed value of $\lambda_{\mathrm{m}}$, repeat steps 10 and 11 once more for the improved values of $\Phi_{i}, \Psi_{i}$ and $F_{s}$.

13. Calculate $E_{i}$ using Equation 9.

14. Calculate $\lambda_{\mathrm{m}}$ using Equation 22.

15. With the updated values of $F_{s}$ and $\lambda_{\mathrm{m}}$, repeat steps $10-15$ until the difference in the values of $F_{s}$ and $\lambda_{\mathrm{m}}$ for two consecutive iterations fall below the tolerances $t_{1}$ and $t_{2}$, respectively. A tolerance of 0.001 was considered for both cases in this analysis.

16. Store the $F_{s}$ value for the chosen slip surface.

17. Choose a different slip surface and return to step 4. Repeat up to step 17 for all the possible slip surfaces.

18. Find the minimum of all the $F_{s}$ values obtained in step 17 to obtain the factor of safety and the critical slip surface of the pile-stabilised slope.
The above algorithm was coded in Matlab software (R2020b). The algorithm can also be used to obtain the $F_{s}$ of soil slopes that are not stabilised by piles if $R_{i}$ and $T_{i}$ are calculated using Equations 12 and 13, respectively, for all slices and the scale factor $(\lambda)$ is determined using Equation 8. Also, for the no-pile condition, the division of the slope into three zones is not needed. Figure 6 shows the typical output plot with various slip surfaces considered and the failure surface corresponding to the minimum $F_{s}$, for a particular pile position and slope angle. The abscissa and ordinate represent the respective horizontal and vertical dimensions of the model considered in the analysis. The critical slip surface is represented by red colour and the green lines represent the ground surface. The line with star marks at either ends denotes the location of the pile.

\section{Comparison of algorithm with finite-element modelling and the limit equilibrium method}

Factor of safety values for soil slopes with and without piles obtained from the proposed algorithm were compared with that determined using finite element modelling. Slopes without pile were modelled both in Plaxis 3D software and the Slope/W program of the GeoStudio software package. The Slope/W program is widely used to obtain the factor of safety of normal soil slopes. Pile-stabilised slopes were simulated only in Plaxis 3D as Slope/W program is a two-dimensional modelling tool.

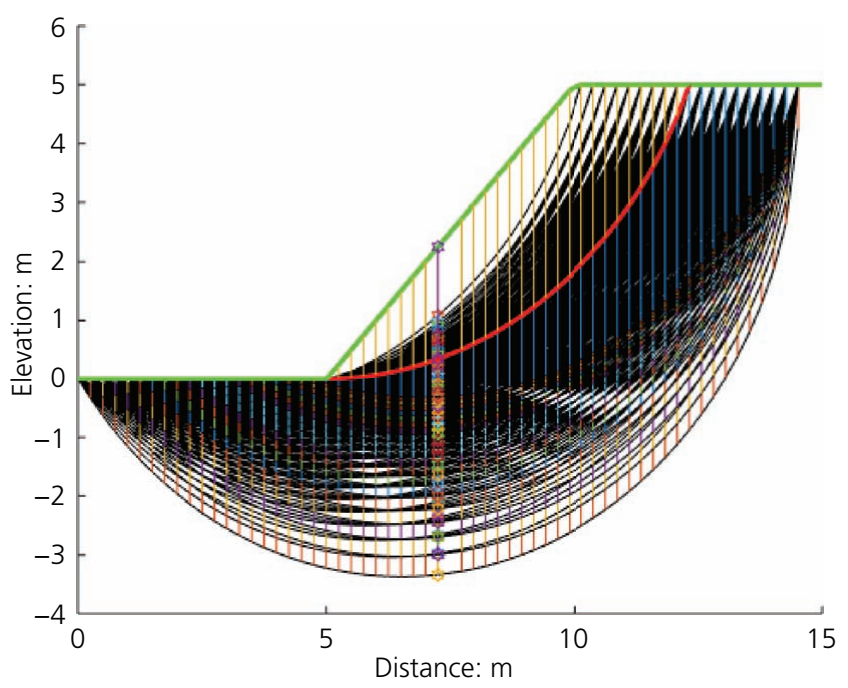

Figure 6. Typical output plot with different slip surfaces and failure surface generated in Matlab

Table 1. Material properties adopted in numerical modelling

$\begin{array}{lccc} & \text { Soil A } & \text { Soil B } & \text { Pile } \\ \gamma . \mathrm{kN} / \mathrm{m}^{3} & 20 & 20 & 25 \\ E: \mathrm{kPa} & 5 \times 10^{3} & 3.5 \times 10^{3} & 7 \times 10^{7} \\ \mu & 0.25 & 0.25 & 0.15 \\ \mathrm{c}: \mathrm{kPa} & 0 & 40 & - \\ \phi:{ }^{\circ} & 32 & 20 & - \\ \psi . & 0 & 0 & -\end{array}$


A soil slope having a height of $5 \mathrm{~m}$ and slope angle $(\beta)$ of $26.6^{\circ}$ $(1 \mathrm{~V}: 2 \mathrm{H})$ was modelled using various soil conditions and pile parameters as shown in Table 1. Two different soil conditions represented as Soil A (sand) and Soil B ( $c-\phi$ soil) were chosen for the analyses. In the case of the pile-stabilised slope, a row of $0.3 \mathrm{~m}$ and $1 \mathrm{~m}$ dia. piles at a spacing of three times the diameter was considered. Modelling of slope sections with different number of piles was carried out and the results were essentially the same. The model presented here was the one with nine piles.

Figure 7 displays the slope model constructed in limit equilibrium slope stability mode of Slope/W. Morgenstern-Price analysis type was selected with a half-sine side function as adopted in the proposed algorithm. The soil was characterised as Mohr-Coulomb material and the phreatic line was assumed to be at a greater depth below base of the model. The potential slip surfaces for analysis were defined using entry and exit points with the specified 'radius tangential lines' intrinsic option available in the program.

In case of Plaxis 3D analysis, three-dimensional (3D) models of soil slope (and piles) were generated using 10-nodded tetrahedral elements. The built-in 'soil and interface' material type was selected to model soil and piles. The soil was modelled as Mohr-Coulomb material. The piles were modelled as concrete piles using the linear-elastic material model. The boundary condition at all the vertical surfaces was set to normally fixed. The horizontal surface at the base was fully restrained. The slope surface and the horizontal surfaces at the top were set to free. Sufficient depth of soil was provided below the pile tip so that the influence of boundary was negligible. The effect of construction sequence and pile installation were not considered in the present analysis. The soil mass and the piles were activated in the initial phase and a $K_{\mathrm{o}}$ calculation type was chosen. A null plastic analysis in phase 2 of the staged construction loading type was carried out to activate the gravity loads due to the soil mass and the row of piles. The plastic analysis was followed by the inbuilt safety analysis with updated mesh to determine the factor of

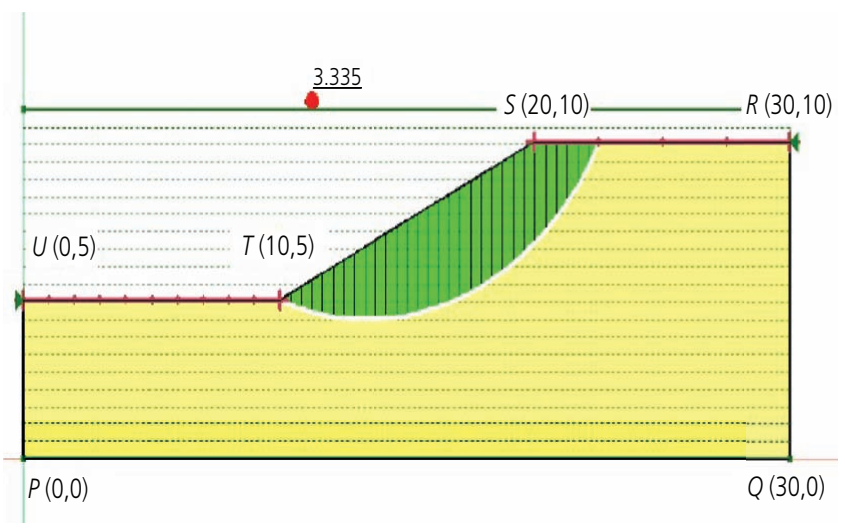

Figure 7. $F_{S}$ computation results in slope/W, GeoStudio safety of pile-stabilised slopes. The principle of strength reduction was used to obtain the factor of safety. Factor of safety is defined as the ratio of maximum available shear strength to minimum shear strength required for equilibrium. The standard Coulomb condition is introduced to strength reduction method to obtain Equation 23 for factor of safety (Brinkgreve et al., 2018).

23

Factor of safety $=\frac{c-\sigma_{\mathrm{m}} \tan \phi}{c_{r}-\sigma_{\mathrm{m}} \tan \phi_{\mathrm{r}}}$

where, $c$ and $\phi$ are input strength parameters which are reduced to $c_{\mathrm{r}}$ and $\phi_{\mathrm{r}}$, the minimum required strength parameters, and $\sigma_{\mathrm{n}}$ is the normal stress component. In the strength reduction approach of Plaxis 3D, both $c$ and $\phi$ are reduced by a common multiplier $\Sigma M_{\mathrm{sf}}$ as given in Equation 24. This parameter is incrementally increased till failure and the value of $M_{\mathrm{sf}}$ at failure is reported as factor of safety (Brinkgreve et al., 2018).

24. $\sum M_{\mathrm{sf}}=\frac{c}{c_{\mathrm{r}}}=\frac{\tan \phi}{\tan \phi_{\mathrm{r}}}$

Figure 8 shows the total deformation contour obtained from the safety analysis of pile-stabilised slope in Plaxis 3D. Table 2 summarises the $F_{s}$ values for slopes without piles for different soil types obtained from the proposed algorithm and finite-element modelling.

The comparison of $F_{S}$ values of pile-stabilised slopes for the case of 0.3 and $1 \mathrm{~m}$ dia. piles, estimated using Plaxis 3D, and the developed

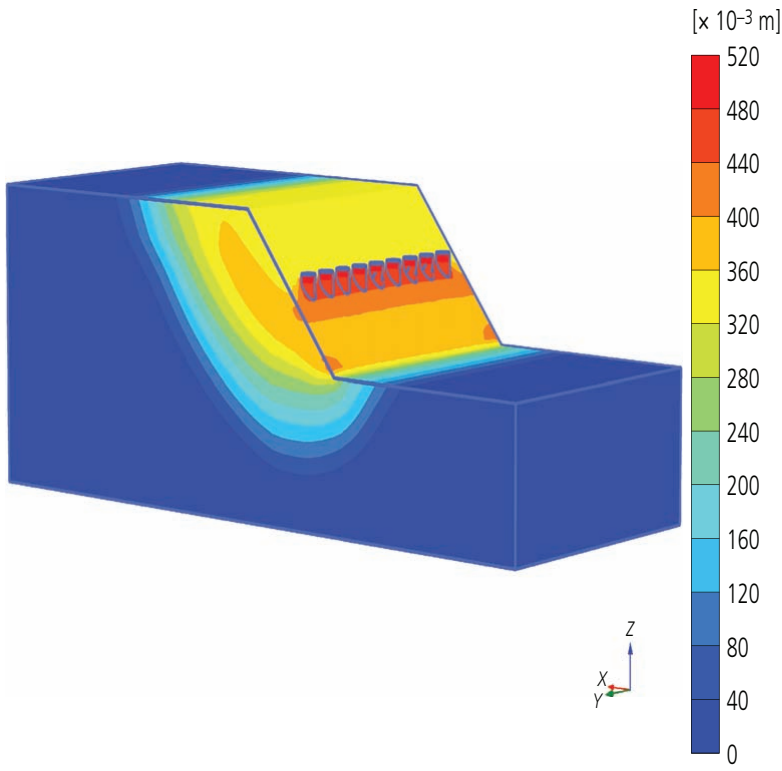

Figure 8. Total deformation contour after safety analysis of pilestabilised slope model in Plaxis 3D 
Table 2. Comparison of $F_{s}$ values obtained from numerical modeling and proposed algorithm for slopes without piles

$\begin{array}{lcc}\text { Method } & \text { Soil A } & \text { Soil B } \\ \text { GeoStudio (slope/W) } & 1.55 & 3.15 \\ \text { Plaxis 3D } & 1.53 & 3.08 \\ \text { Proposed algorithm } & 1.52 & 3.15\end{array}$

Table 3. Comparison of $F_{s}$ values obtained from numerical modeling and proposed algorithm for pile-stabilised slopes

\begin{tabular}{llcc} 
Pile diameter & \multicolumn{1}{c}{ Method } & Soil A & Soil B \\
$0.3 \mathrm{~m}$ & Plaxis 3D & 1.72 & 3.32 \\
$0.3 \mathrm{~m}$ & Proposed algorithm & 1.71 & 3.42 \\
$0.3 \mathrm{~m}$ & 'Additional term' method & 1.94 & 3.83 \\
$1.0 \mathrm{~m}$ & Plaxis 3D & 2.15 & 3.92 \\
$1.0 \mathrm{~m}$ & Proposed algorithm & 1.98 & 4.03 \\
$1.0 \mathrm{~m}$ & 'Additional term' method & 2.47 & 4.31 \\
\hline
\end{tabular}

algorithm are presented in Table 3. The $F_{s}$ values for the same slope and pile-dimensions, when computed by taking the pile contribution explicitly as an additional term, are also presented in Table 3. This was obtained by adding $P$ (Equation 1 ) to the numerator of equation for $F_{s}$ (Equation 6) wherein $R_{i}, t_{i}$ and $\lambda$ were obtained using Equations 12, 13 and 8, respectively, as discussed previously for the case of non-stabilised slopes.

As is evident from the tables, the factor of safety values for both normal and stabilised slopes predicted using the proposed method were in close agreement with that obtained from the numerical analyses. This implies that the proposed algorithm can be used to compute the $F_{S}$ quickly, unlike the finite-element packages which require a significant amount of time to generate a model and calculate the results. It can be observed from Table 3 that

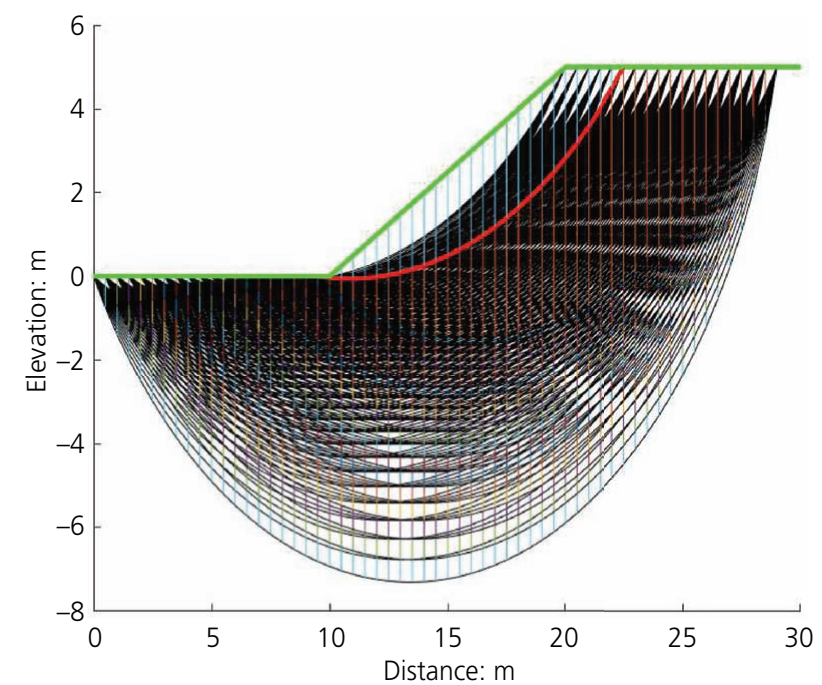

(a) considering the resistance offered by piles as an additional term in the equation for $F_{s}$, as conventionally done in practice, leads to an over-prediction. The 'additional term' method also fails to capture the effect of pile location. In reality, the $F_{s}$ varies with the location of piles, as discussed in next section.

\section{Change in critical failure plane}

The installation of piles in a slope modifies its critical slip surface. The existing practices do not consider the change in critical slip surface and compute the factor of safety corresponding to the same slip surface as that of un-stabilised slopes. The proposed algorithm identifies the new critical slip surface formed due to the introduction of piles and computes the $F_{S}$ corresponding to the new surface. To demonstrate the modification of slip surface due to the introduction of stabilising piles, the analyses were carried out for without and with stabilising piles cases using the proposed algorithm. Piles having a diameter of $1 \mathrm{~m}$ spaced at a centre-to-centre distance, $n=3$, in a typical $c-\phi$ soil slope with $c=30 \mathrm{kN} / \mathrm{m}^{2}, \phi=20^{\circ}$, unit weight, $\gamma=20 \mathrm{kN} / \mathrm{m}^{3}$, and slope angle $\beta=26.5(2 \mathrm{H}: 1 \mathrm{~V})$ were considered for the analyses. When all other factors are kept constant, the variation in the critical slip surfaces for the case of without and with stabilising piles obtained using the proposed algorithm is given in Figures 9(a) and 9(b), respectively. The colour codes adopted for Figure 6 are applicable to Figure 9 as well.

\section{Determination of pile location and spacing}

The factor of safety of pile-stabilised slopes is influenced by the location of the pile. Currently, the determination of optimal location of pile (OPL) is a time-consuming task which involves multiple finite-element modelling iterations, consuming considerable amounts of time. A new a straightforward technique to determine the OPL is presented in this work. The distance of the pile from the toe of the slope can be easily taken as an additional variable in the proposed

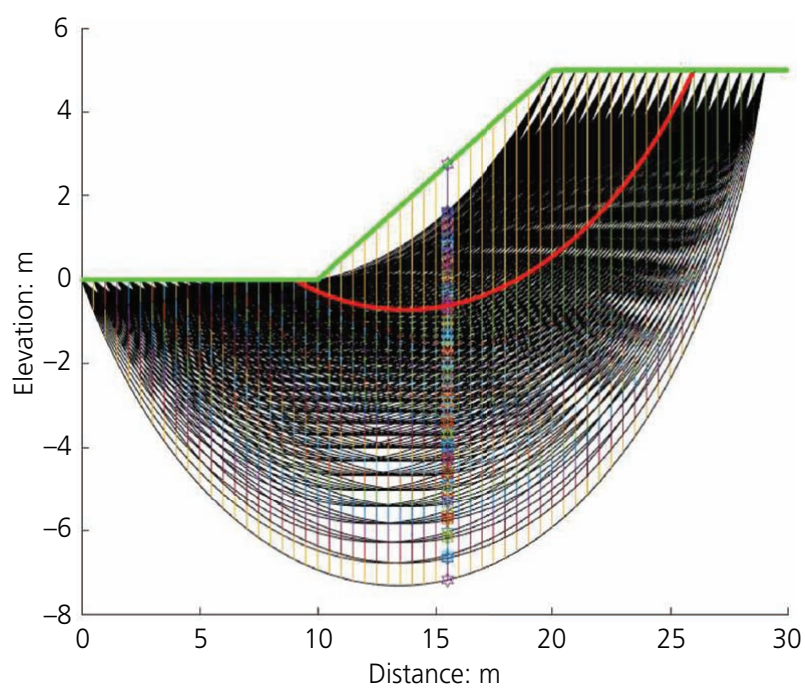

(b)

Figure 9. Critical slip surface generated using proposed algorithm (a) without pile and (b) with pile 


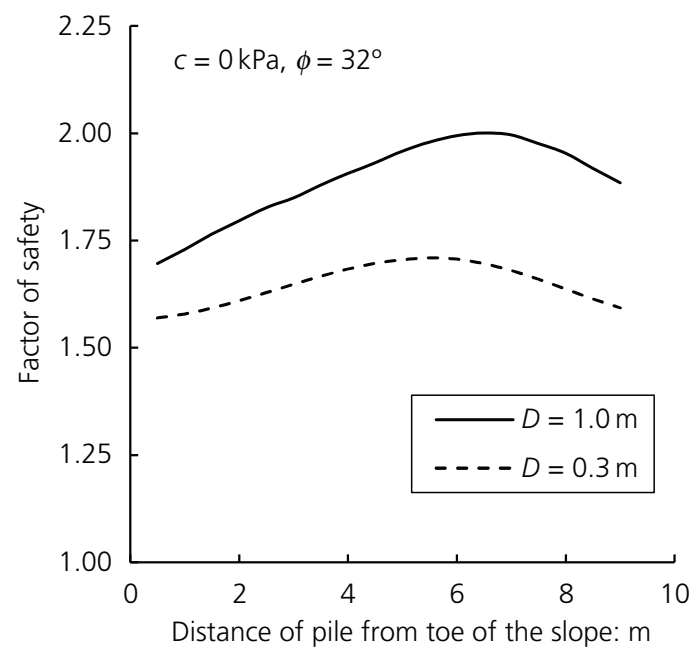

(a)

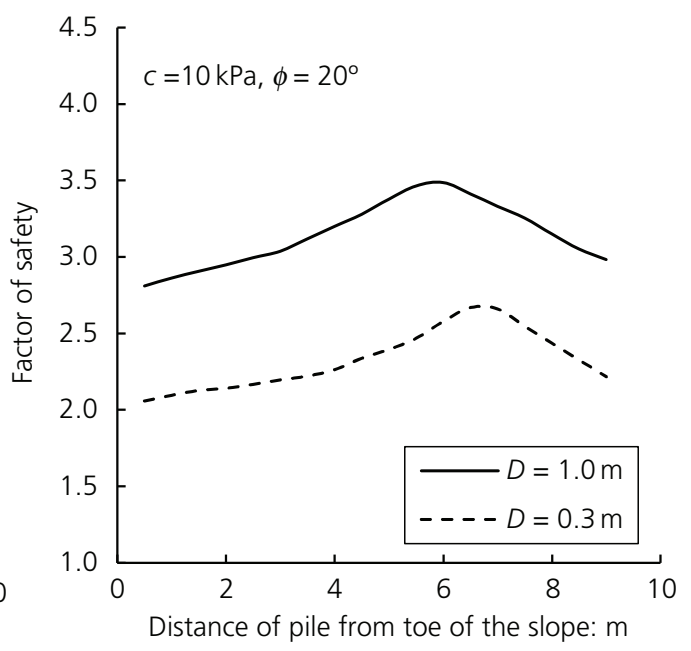

(b)

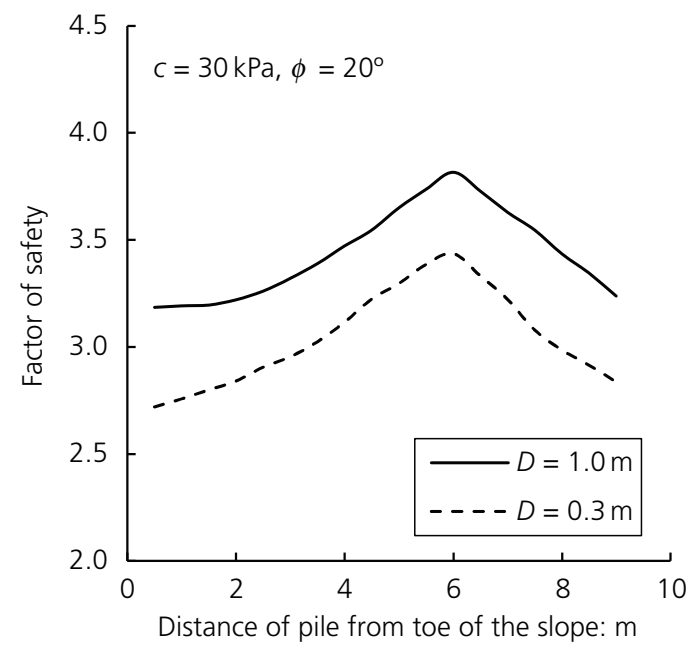

(c)

Figure 10. Variation of $F_{s}$ with location of the piles: (a) soil (i), (b) soil (ii) and (c) soil (iii)

algorithm presented in the previous section and the $F_{s}$ value corresponding to each pile location can be computed. Three typical scenarios, (i) $c=0 \mathrm{kN} / \mathrm{m}^{2}, \phi=32^{\circ}$, (ii) $c=10 \mathrm{kN} / \mathrm{m}^{2}, \phi=20^{\circ}$ and (iii) $c=30 \mathrm{kN} / \mathrm{m}^{2}, \phi=20^{\circ}$, were considered. A pile-stabilised slope installed with ( i) $D=0.3 \mathrm{~m}$ and (ii) $D=1 \mathrm{~m}$ piles, spaced at a centerto-center distance, $n=3$, and a slope angle $\beta=26.5^{\circ}$ (2H:1V) was adopted. The unit weight of soil was assumed as $20 \mathrm{kN} / \mathrm{m}^{3}$. The total length of the base of the slope was adopted as $10 \mathrm{~m}$. The variation of $F_{s}$ with the location of pile for cases (i)-(iii) is presented in Figure 10(a)-(c).

The optimal location of pile obtained using the proposed method is in accordance with the results of past finite-element analyses found in literature. Hassiotis et al. (1997) suggested that the piles installed between the middle and the crest of the slope are most effective. In case of homogenous purely cohesive soil, Lee et al. (1995) showed that the most effective position of piles is close to the crest of the slope.
The finite-element analysis presented in the paper by Cai and Ugai (2000) indicates that the piles located at the middle of the slope provide the highest factor of safety. Ausilio et al. (2001) also suggest placing the piles in the upper-middle portion of the slope for efficient stabilisation. As can be observed from Figure 10, the $F_{s}$ values initially increase with the distance of pile from the toe of the slopes, reach a peak value and then decrease as the piles move further away from the toe. In case of sandy soil, the maximum factor of safety is obtained when the piles are located around the mid-slope. On the other hand, as the soil becomes cohesive, the maximum $F_{s}$ value is found to occur at a pile location above the mid-slope. However, the location of pile corresponding to the peak value of $F_{s}$ can not be readily called the OPL as it is also influenced by various other factors, for example, the access to the slope, space for construction and so on. Nevertheless, the proposed algorithm can be easily used to obtain the variation of factor of safety with location of pile, which in turn can be used by engineers to choose the location based on other field constraints. 
The variation of $F_{s}$ with the ratio of pile-spacing to diameter ( $n=s / D ; D=0.3$ ) is presented in Figure 11 for the case of soils (i)-(iii). As the soil-arching effect is more significant when the piles are placed closer, the resistance they offer will be greater. Therefore, higher $F_{s}$ is found to occur at smaller pile-spacing. Further, it can be observed that, beyond the pile-spacing of $4-5 D$, the change in $F_{s}$ is negligible, because of lower pile-contribution.

\section{Conclusions}

In this work, a new algorithm is proposed to compute the factor of safety of pile-stabilised slopes. The proposed algorithm involves an iterative procedure which models the progressive transfer of additional resistance offered by piles. The pilestabilised slope is divided into three zones (pre-arching, arching and post-arching zone) and a pressure-based method proposed by Neeraj and Thiyyakkandi (2020) is extended to obtain the force on each zone. Thereby, the effect of soil arching on the loadtransfer mechanism of pile-stabilised slopes was intrinsically incorporated in the proposed algorithm. The comparison between $F_{s}$ values computed using the proposed algorithm and those obtained using finite-element modelling showed that the algorithm can be used as a quick, simple and reliable technique to estimate the factor of safety of pile-stabilised slopes. The conventional method of computing $F_{s}$ wherein the pile-contribution is considered as an additional term, was found to over-predict the values. Unlike the conventional methods, the proposed algorithm incorporates the modified slip surface while computing the $F_{s}$, which significantly affects the estimated value. Subsequently, the variation of $F_{s}$ with the pile location along the slope was studied. It was found that, for frictional soil, the mid-slope was the ideal location of the pile, while, as the cohesion value increased, the maximum $F_{S}$ occurred when the piles were placed above the middle of slope. The factor of safety was found to reduce with an increase in pile-spacing due to poor contribution from the pile. Apparently, a pile-spacing greater than four to five times the diameter of piles was found to be ineffective in stabilising the

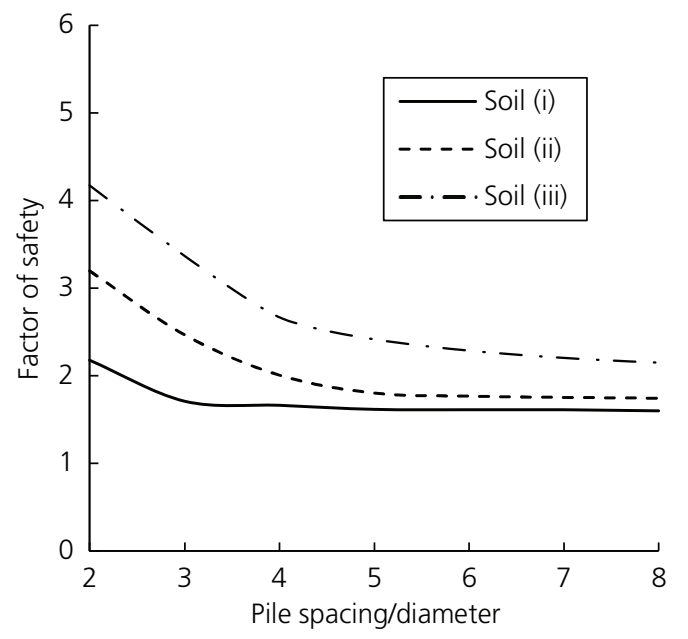

Figure 11. Variation of $F_{s}$ with pile spacing pile. However, the optimal pile location and spacing should only be determined by studying other field constraints and the cost involved. The experimental validation of the proposed method is also warranted before field use.

\section{Acknowledgments}

The first author gratefully acknowledges the financial support provided by the Ministry of Education (MoE), India, for completion of this work.

\section{Appendix}

A: formulation of vertical average stress $\bar{\sigma}_{\mathrm{v}}$

The enlarged view of the differential element $E F F^{\prime} E^{\prime}$ (Figure 2) is shown in Figure 12. The triangle $L F F^{\prime}$ is in equilibrium state, and therefore, it can be ignored in the analysis of vertical equilibrium of the whole differential element (He et al., 2015a; Neeraj and Thiyyakkandi, 2020). The minor principal stress $\sigma_{3}$ acts on plane $L F^{\prime}$, which can be resolved in vertical direction to obtain $\sigma_{3 \mathrm{v}}$ as

25. $\sigma_{3 \mathrm{v}}=\sigma_{3} \frac{\sin \xi \cos \beta}{\cos (\xi+\beta)}$

Using the principles of origin of planes, it can be proved that:

$\xi=\frac{\pi}{4}+\frac{\phi}{2}-\theta_{1} ; \theta=\frac{1}{2}\left(\phi-\beta+\cos ^{-1} \frac{\sin \beta}{\sin \phi}\right) ;$ and

$\theta_{1}=\frac{1}{2}\left(\phi+\beta+\cos ^{-1} \frac{\sin \beta}{\sin \phi}\right)$

where $\theta$ is the angle between the slip plane and the slope surface; $\theta_{1}$ is the angle between the slip plane and the horizontal; $\beta$ is the slope angle; and $\phi$ is the angle of internal friction. Shear stress at face $E E^{\prime}$ is given by:

26. $\tau=c+\sigma_{h} \tan \phi=c+\left(k_{\mathrm{an}} \bar{\sigma}_{\mathrm{v}}+T\right) \tan \phi$

Considering the vertical force equilibrium of the differential element $d z$,

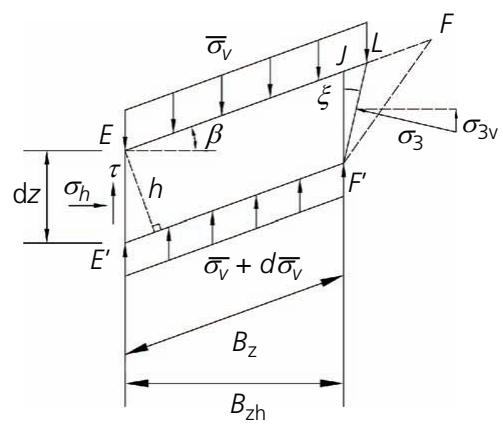

Figure 12. Enlarged view of the differential element in the vertical arching zone 
27.

$$
\begin{aligned}
& \tau d z+\left(\bar{\sigma}_{\mathrm{v}}+d \bar{\sigma}_{\mathrm{v}}\right) B^{\prime}+\sigma_{3 \mathrm{v}} d z-\bar{\sigma}_{\mathrm{v}} B^{\prime}-\sigma_{h} \\
& \tan \beta d z-\gamma B^{\prime} h=0
\end{aligned}
$$

Where $B^{\prime}=(H-z) \cos \theta_{1} / \sin \theta$ and $h=d z \cos \beta$.

Substituting Equation 26, Equation 2, Equation 25 and Equation 27 and rearranging,

28. $\frac{d \bar{\sigma}_{\mathrm{v}}}{d z}+\bar{\sigma}_{\mathrm{v}}\left(\frac{C_{1}}{H-z}\right)+\frac{C_{2}}{H-z}-\gamma \cos \beta=0$

$C_{1}$ and $C_{2}$ can be obtained from Equation 3.

Equation 22 is in the $d y / d x+P y=Q$ form and can be integrated using the method of integration factor to obtain $\bar{\sigma}_{\mathrm{v}}$.

29. $\left[\bar{\sigma}_{\mathrm{v}}+\frac{\gamma \cos \beta(H-z)}{1-C_{1}}+\frac{\mathrm{C}_{2}}{\mathrm{C}_{1}}\right](H-z)^{-\mathrm{C}_{1}}=C$

where, $C$ is the constant of integration. Applying the boundary condition, $\bar{\sigma}_{\mathrm{v}}=0$ at $z=0$, in Equation 29 gives:

30.

$$
C=\left[\frac{\gamma \cos \beta H}{1-C_{1}}+\frac{C_{2}}{C_{1}}\right](H)^{-C_{1}}
$$

Substituting for $C$ (Equation 30) in Equation 29 and re-arranging,

31.

$$
\begin{aligned}
\bar{\sigma}_{\mathrm{v}}= & \frac{\gamma \cos \beta H}{1-C_{1}}\left[\left(1-\frac{z}{H}\right)^{C_{1}}-\left(1-\frac{z}{H}\right)\right] \\
& +\frac{C_{2}}{C_{1}}\left[\left(1-\frac{z}{H}\right)^{C_{1}}-1\right]
\end{aligned}
$$

\section{B: resultant forces and point of action}

The resultant reaction on pre-arching zone, $P_{\mathrm{o}}$, and the resultant lateral force transferred to the post-arching zone, $P_{i}$, can be obtained by integrating the force per unit length along the depth.

32.

$$
P_{\mathrm{o}}=\int_{0}^{H} \sigma_{\mathrm{o}}(s) d z \quad \text { and } \quad P_{\mathrm{i}}=\int_{0}^{H} \sigma_{\mathrm{i}}(s-D) d z
$$

Here, $\sigma_{o}$ and $\sigma_{i}$ are the stresses along the outer and inner planes of the arching zone, respectively (Figure 1). The stress $\sigma_{i}$ is given by Equation 2 and the stress $\sigma_{o}$ is related to $\sigma_{i}$ as (Neeraj and Thiyyakkandi, 2020):
$\sigma_{\mathrm{o}}=\sigma_{\mathrm{i}}\left(\frac{\sqrt{n^{2}+1}}{n-1}\right)^{N-1}+\frac{2 c \sqrt{N}}{N-1}\left[\left(\frac{\sqrt{n^{2}+1}}{n-1}\right)^{N-1}-1\right]$

33.

Substituting Equations 2 and 33 in Equation 32 and integrating yields,

$$
\begin{aligned}
P_{\mathrm{o}}= & n D H\left[( \frac { \sqrt { n ^ { 2 } + 1 } } { n - 1 } ) ^ { N - 1 } \left\{\frac{K_{\mathrm{an}} \gamma H \cos \beta}{1-C_{1}}\right.\right. \\
& \left.\left(\frac{1}{1+C_{1}}-\frac{1}{2}\right)+\frac{C_{2}}{C_{1}}\left(\frac{1}{1+C_{1}}-1\right)+T\right\} \\
& \left.+\frac{2 c \sqrt{N}}{N-1}\left\{\left(\frac{\sqrt{\mathrm{n}^{2}+1}}{\mathrm{n}-1}\right)^{N-1}-1\right\}\right]
\end{aligned}
$$

34.

$$
\begin{aligned}
P_{\mathrm{i}}= & (n-1) D H\left[\frac{K_{\mathrm{an}} \gamma H \cos \beta}{1-C_{1}}\left(\frac{1}{1+C_{1}}-\frac{1}{2}\right)\right. \\
& \left.+\frac{C_{2}}{C_{1}}\left(\frac{1}{1+C_{1}}-1\right)+T\right]
\end{aligned}
$$

To obtain the points of application of these forces, the moment about the point where the piles intersect the slip surface is taken, that is,

36.

$$
\begin{aligned}
& M_{\mathrm{o}}=\int_{0}^{H} \sigma_{\mathrm{o}}(s)(H-z) d z \text { and } \\
& M_{\mathrm{i}}=\int_{0}^{H} \sigma_{\mathrm{i}}(s-D)(H-z) d z
\end{aligned}
$$

Using Equations 2, 33-36, the point of application of forces from the slip surface can obtained as:

$$
h_{\mathrm{o}}=\frac{M_{\mathrm{o}}}{P_{\mathrm{o}}} \quad \text { and } \quad h_{\mathrm{i}}=\frac{M_{\mathrm{i}}}{P_{\mathrm{i}}}
$$

\section{REFERENCES}

Ahmed S (2017) Matlab Script for Slope Stability Calculations with Comsol Multiphysics. PhD thesis, École de technologie supérieure, Université du Québec, Montreal, Canada. 
Ashour M and Ardalan H (2012) Analysis of pile stabilized slopes based on soil-pile interaction. Computers and Geotechnics 39: 85-97, https:// doi.org/10.1016/j.compgeo.2011.09.001.

Atarigaya BD (2016) Numerical Modeling and Simulation of the Stability of Earth Slopes. $\mathrm{PhD}$ thesis, University of Ghana, Accra, Ghana.

Ausilio E, Conte E and Dente G (2001) Stability analysis of slopes reinforced with piles. Computers and Geotechnics 28(8): 591-611, https://doi.org/10.1016/S0266-352X(01)00013-1.

Brinkgreve R, Engin E and Swolfs W (2018) PLAXIS 3D Tutorial Manual 2018. Plaxis bv, Delft, the Netherlands.

Cai F and Ugai K (2000) Numerical analysis of the stability of a slope reinforced with piles. Soils and Foundations 40(1): 73-84, https://doi. org/10.3208/sandf.40.73.

Di Laora R, Maiorano RMS and Aversa S (2017) Ultimate lateral load of slope-stabilising piles. Géotechnique Letters 7(3): 237-244, https://doi. org/10.1680/jgele.17.00038.

Duncan JM (1996) State of the art: limit equilibrium and finiteelement analysis of slopes. Journal of Geotechnical Engineering 122(7): 577-596, https://doi.org/10.1061/(ASCE)0733-9410(1996) 122:7(577).

Ellis E, Durrani IK and Reddish DJ (2010) Numerical modelling of discrete pile rows for slope stability and generic guidance for design. Géotechnique 60(3): 185-195, https://doi.org/10.1680/geot.7.00090.

Firat S (2009) Stability analysis of pile-slope system. Scientific Research and Essays 4(9): 842-852, https://doi.org/10.5897/SRE. 9000860 .

Griffiths D and Lane P (1999) Slope stability analysis by finite elements. Géotechnique 49(3): 387-403, https://doi.org/10.1680/geot.1999.49.3. 387.

Harrop-Williams K (1989) Arch in soil arching. Journal of Geotechnical Engineering 115(3): 415-419, https://doi.org/10.1061/(ASCE)07339410(1989)115:3(415).

Hassiotis S, Chameau J and Gunaratne M (1997) Design method for stabilization of slopes with piles. Journal of Geotechnical and Geoenvironmental Engineering 123(4): 314-323, https://doi.org/10 1061/(ASCE)1090-0241(1997)123:4(314).

He Y, Hemanta H, Noriyuki Y and Zheng H (2015a) Evaluating the effect of slope angle on the distribution of the soil-pile pressure acting on stabilizing piles in sandy slopes. Computers and Geotechnics 69: 153-165, http://dx.doi.org/10.1016/j.compgeo.2015.05.006.

He Y, Hemanta H, Noriyuki Y et al. (2015b) Estimation of lateral force acting on piles to stabilize landslides. Natural Hazards 79(3): 1981-2003, https://doi.org/10.1007/s11069-015-1942-0.

Ito T and Matsui T (1975) Methods to estimate lateral force acting on stabilizing piles. Soils and Foundations 15(4): 43-59, https://doi.org/ 10.3208/sandf1972.15.443.

Jeong S, Kim B, Won J and Lee J (2003) Uncoupled analysis of stabilizing piles in weathered slopes. Computers and Geotechnics 30(8): 671-682, https://doi.org/10.1016/j.compgeo.2003.07.002.
Kourkoulis R, Gelagoti F, Anastasopoulos I and Gazetas G (2011) Hybrid method for analysis and design of slope stabilizing piles. Journal of Geotechnical and Geoenvironmental Engineering 138(1): 1-14, https://doi.org/10.1061/(ASCE)GT.1943-5606.0000546.

Lee C, Hull T and Poulos H (1995) Simplified pile-slope stability analysis. Computers and Geotechnics 17(1): 1-16, https://doi.org/10.1016/ 0266-352X(95)91300-S.

Li X and Wei S (2018) A calculation method for the distribution of lateral force acting on stabilizing piles considering soil arching effect. Indian Geotechnical Journal 49(1): 132-139, https://doi.org/10.1007/s40098018-0307-5.

Liang R and Zeng S (2002) Numerical study of soil arching mechanism in drilled shafts for slope stabilization. Soils and Foundations 42(2): 83-92, https://doi.org/10.3208/sandf.42.283.

Liang RY, Joorabchi AE and Li L (2014) Analysis and design method for slope stabilization using a row of drilled shafts. Journal of Geotechnical and Geoenvironmental Engineering 140(5): 04014001, https://doi.org/10.1061/(ASCE)GT.1943-5606.0001070.

Lirer S (2012) Landslide stabilizing piles: experimental evidences and numerical interpretation. Engineering Geology 149-150: 70-77, https://doi.org/10.1016/j.enggeo.2012.08.002.

Morgenstern N and Price V (1965) The analysis of the stability of general slip surfaces. Géotechnique 15(1): 79-93, https://doi.org/10.1680/geot. 1965.15.1.79.

Neeraj CR (2019) Analysis of Pile-Stabilised Slopes Incorporating Horizontal and Vertical Arching. MS thesis, Indian Institute of Technology, Palakkad, India.

Neeraj CR and Thiyyakkandi S (2020) Estimation of lateral pile resistance incorporating soil arching in pile-stabilized slopes. Geomechanics and Engineering 23(5): 481-491, https://doi.org/10.12989/gae.2020.23.5. 481.

Summersgill FC, Kontoe S and Potts DM (2018) Stabilisation of excavated slopes in strain-softening materials with piles. Géotechnique 68(7): 626-639, https://doi.org/10.1680/jgeot.17.P.096.

Song Y-S, Hong W-P and Woo K-S (2012) Behavior and analysis of stabilizing piles installed in a cut slope during heavy rainfall. Engineering Geology 129-130: 56-67, https://doi.org/10.1016/j. enggeo.2012.01.012

Tsuchida T and Athapaththu A (2014) Practical slip circle method of slices for calculation of bearing capacity factors. Soils and Foundations 54(6): 1127-1144, https://doi.org/10.1016/j.sandf.2014. 11.008.

Won J, You K, Jeong S and Kim S (2005) Coupled effects in stability analysis of pile-slope systems. Computers and Geotechnics 32(4): 304-315, https://doi.org/10.1016/j.compgeo.2005.02.006.

Zhu D, Lee C, Qian Q and Chen G (2005) A concise algorithm for computing the factor of safety using the Morgenstern-Price method. Canadian Geotechnical Journal 42(1): 272-278, https://doi.org/10. 1139/t04-072.

\section{How can you contribute?}

To discuss this paper, please submit up to 500 words to the editor at journals@ice.org.uk. Your contribution will be forwarded to the author(s) for a reply and, if considered appropriate by the editorial board, it will be published as a discussion in a future issue of the journal. 